\title{
In Situ Microbial Community Control of the Stability of Bio-reduced Uranium
}

\author{
B.R. Baldwin ${ }^{1}$, A.D. Peacock ${ }^{1}$, C.T. Resch ${ }^{2}$, E. Arntzen ${ }^{2}$, A.N. Smithgall ${ }^{1}$, S. Pfiffner, M. Gan ${ }^{1}$, \\ J.P. McKinley ${ }^{2}$, P.E. Long ${ }^{2}$, and David C. White ${ }^{1}$ \\ ${ }^{1}$ Center for Biomarker Analysis, University of Tennessee, Knoxville, TN 37932 \\ ${ }^{2}$ Pacific Northwest National Laboratory, P.O. Box 999 Richland, WA 99352
}

\section{INTRODUCTION}

In aerobic aquifers typical of many Department of Energy (DOE) legacy waste sites, uranium is present in the oxidized U(VI) form which is more soluble and thus more mobile. Field experiments at the Old Rifle UMTRA site have demonstrated that biostimulation by electron donor addition (acetate) promotes biological $\mathrm{U}(\mathrm{VI})$ reduction (2). However, $\mathrm{U}(\mathrm{VI})$ reduction is reversible and oxidative dissolution of precipitated U(IV) after the cessation of electron donor addition remains a critical issue for the application of biostimulation as a treatment technology. Despite the potential for oxidative dissolution, field experiments at the Old Rifle site have shown that rapid reoxidation of bio-reduced uranium does not occur and $\mathrm{U}(\mathrm{VI})$ concentrations can remain at approximately $20 \%$ of background levels for more than one year. The extent of postamendment $\mathrm{U}(\mathrm{VI})$ removal and the maintenance of bioreduced uranium may result from many factors including $\mathrm{U}(\mathrm{VI})$ sorption to iron-containing mineral phases, generation of $\mathrm{H}_{2} \mathrm{~S}$ or $\mathrm{FeS}_{0.9}$, or the preferential sorption of $\mathrm{U}(\mathrm{VI})$ by microbial cells or biopolymers, but the processes controlling the reduction and in situ reoxidation rates are not known. To investigate the role of microbial community composition in the maintenance of bioreduced uranium, in-well sediment incubators (ISIs) were developed allowing field deployment of amended and native sediments during on-going experiments at the site. Field deployment of the ISIs allows expedient interrogation of microbial community response to field environmental perturbations and varying geochemical conditions.

\section{OBJECTIVES}

The overall objective of the project is to understand the mechanisms for maintenance of bioreduced uranium in an aerobic aquifer under field conditions after electron donor addition has ended. Extrapolation of laboratory microcosm results to field-scale results is difficult, therefore, in-situ incubators (ISIs) were developed to allow expedient interrogation of the microbial community response to field environmental perturbations. To be a useful tool for investigating the microbial community control of bio-reduced uranium, changes in ISI microbial community composition must mirror those in the subsurface at the site. ISI deployments were designed to validate the ISI approach as a research tool for investigating the role of sulfate-reducing bacteria $(\mathrm{SRB})$ in post-treatment maintenance of bio-reduced uranium.

\section{METHODS}

\section{Field Site}

The Old Rifle UMTRA site (Rifle, $\mathrm{CO}$ ) is a former uranium ore processing facility where spent mill tailings leachate resulted in sediment and groundwater contamination. Under the DOE Environmental Remediation Sciences Program (ERSP), the site has been utilized for extensive field demonstration of bioimmobilization of uranium. The aquifer is an alluvial deposit 
comprised of unconsolidated clay, sand, silt, gravel and cobbles to a depth of approximately 6.9 $\mathrm{m}$ below land surface. Detailed descriptions of the site geology, test plots, and acetate injection experiments are available elsewhere $(2,6,16)$ but will be summarized for the ISI deployments.

\section{In-well Sediment Incubator (ISI) Design}

Figure 1: Conceptual design and top view (section) of In-Well Sediment Incubator (ISI)

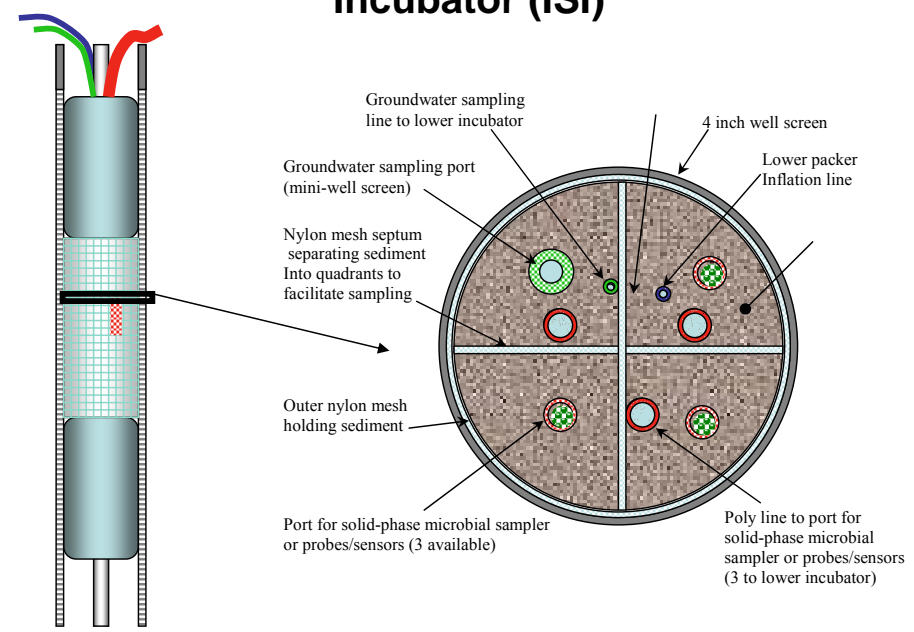

Laboratory scale microcosms allow precise control over system variables, but extrapolation of results to the field scale may be difficult. Therefore, inwell sediment incubators (Figure 1) were developed to permit field deployment of laboratory-manipulated native sediment microbial communities to investigate the role of microbial community composition in the maintenance of bioreduced U(IV). The use of ISIs in conjunction with on-going field activities allows the ready field deployment of multiple permutations of microbial communities under different field conditions. This approach makes it possible to assess actual in situ conditions during the experiment and to directly observe reoxidation (or bioreduction) end points after the field experiment is completed without drilling. The production of in-well sediment incubators is relatively inexpensive and could ultimately become an alternative to field-scale electron donor amendment experiments as a means of assessing site response to bioremediation and long-term stability of both biostimulated and naturally bioattenuated sites.

The prototype ISIs were constructed from $0.5 \mathrm{~m}$ sections of 3 inch Schedule 40 PVC pipe (Figure 2). Slots were removed from the ISI body to accommodate the porous $(90-130 \mu \mathrm{m})$ polyethylene liner which retained loaded sediment while permitting groundwater flow through the ISI when deployed. PVC end caps to seal the ISI body were constructed with tubing pass-throughs for groundwater monitoring. For the prototype ISI, packers inflated with nitrogen gas were used to isolate the ISI vertically within the well. In subsequent deployments, end caps equipped with o-rings

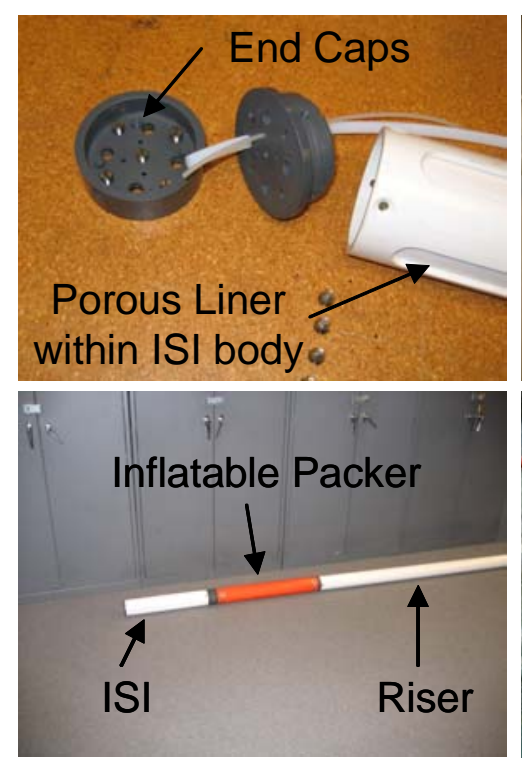

Figure 2: Prototype ISI

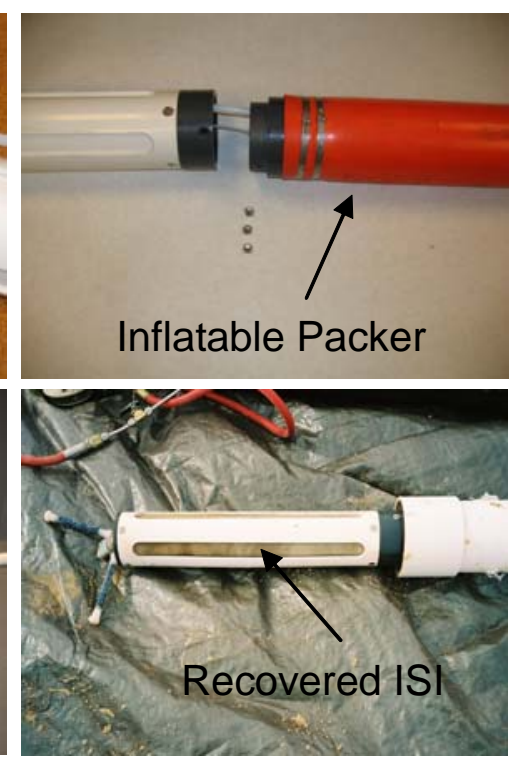


were used for vertical isolation. ISIs were attached to PVC risers to be deployed approximately $4.9 \mathrm{~m}$ below the top of the well casing.

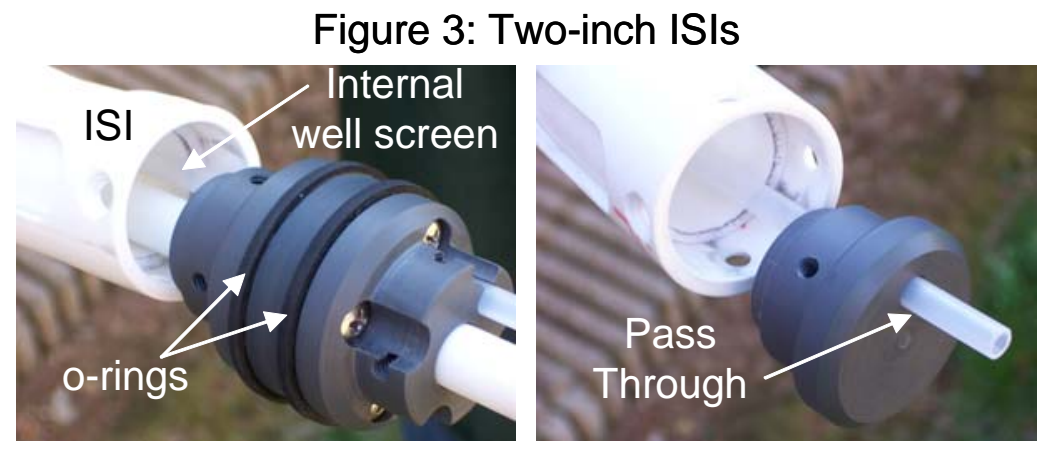

The ISIs constructed for the Rifle deployments were 3 inches in diameter, however, 2 inchdiameter monitoring wells are more common at other UMTRA sites. Therefore, 2 inch ISIs, which incorporated several design improvements, were constructed for the ongoing Rifle IFC project (Figure 3). The inflatable packers were replaced with external o-rings to simplify field operations while maintaining vertical isolation. An internal well screen was added to allow electron donor additions during ISI deployments. A complete pass through was also added to permit continued groundwater sampling without removing deployed ISIs.

\section{Generation of Reduced Rifle Aquifer Sediment}

Native Rifle Aquifer Background Sediments (RABS) were used as the starting material for all inwell sediment incubator (ISI) studies conducted at the site. To investigate the microbial community response under field conditions, ISIs containing either Rifle Aquifer Background Sediment (RABS), Reduced Rifle sediments (R-RABS), Rifle sediments under iron-reducing conditions (IR), or Rifle sediments under sulfate-reducing conditions (SR) were generated. For reduced sediments, laboratory microcosms containing approximately $500 \mathrm{~g}$ of RABS were amended with $400 \mathrm{~mL}$ IRB $(2.5 \mathrm{~g} / \mathrm{L} \mathrm{NaHCO}, 0.1 \mathrm{~g} / \mathrm{L}$ $\mathrm{KCl}, 1.5 \mathrm{~g} / \mathrm{L} \mathrm{NH} \mathrm{NH}_{4} \mathrm{Cl}, 10 \mathrm{ml} / \mathrm{L}$ Trace mineral Solution (10), $1.0 \mathrm{ml} / \mathrm{L} \quad 10 \mathrm{X} \quad$ Vitamin Solution, $\quad 0.1 \mathrm{~g} / \mathrm{L} \quad \mathrm{MOPS}$, $20 \mathrm{mM} \mathrm{CH} \mathrm{CH}_{3} \mathrm{COONa}, 1.0 \mathrm{ml} / \mathrm{L}$ Figure 4: ISI Preparations $0.1 \%$ Stock Resazurin) or SRB media $\left(0.9 \mathrm{~g} / \mathrm{L} \mathrm{NaCl} 2,0.2 \mathrm{~g} / \mathrm{L} \quad \mathrm{MgCl}_{2}-6 \mathrm{H}_{2} \mathrm{O}, 1.0 \mathrm{~g} / \mathrm{L} \quad \mathrm{NH}_{4} \mathrm{Cl}_{2}\right.$, $10 \mathrm{ml} / \mathrm{L}$ Trace mineral Solution (10), $1.0 \mathrm{ml} / \mathrm{L} 10 \mathrm{X}$ Vitamin Solution, $0.1 \mathrm{~g} / \mathrm{L}$ MOPS, $10 \mathrm{mM}$ $\mathrm{NaSO}_{4}, 40 \mathrm{mM} \mathrm{CH} 3 \mathrm{COONa}$, and $1.0 \mathrm{ml} / \mathrm{L} 0.1 \%$ Stock Resazurin). The redox state was adjusted by addition of $2 \%$ Cysteine- $\mathrm{HCl}$ as needed. The microcosms were shaken every 3-4 days to mix the sediment and were incubated upside down at room temperature for 14 days.

ISIs were loaded with reduced sediment (IR and SR) in an anaerobic chamber and shipped under nitrogen gas to the Rifle site for field deployment. Incubators containing RABS were loaded on site. Subsamples of RABS, IR, and SR were retained prior to deployment (time 0) for PLFA analysis, qPCR enumeration of microbial community members, and DGGE separation and sequence analysis. 


\section{Final ISI Deployments}

In December 2006, a total of six ISIs were deployed at the Old Rifle UMTRA site. ISIs containing IR and SR were deployed in background monitoring well B-02, upgradient of the original test plot. ISIs containing SR and RABS were installed in previously stimulated monitoring well M-02 (acetate injection in 2002 and 2003) located in the original test plot.

Figure 5: Site Map

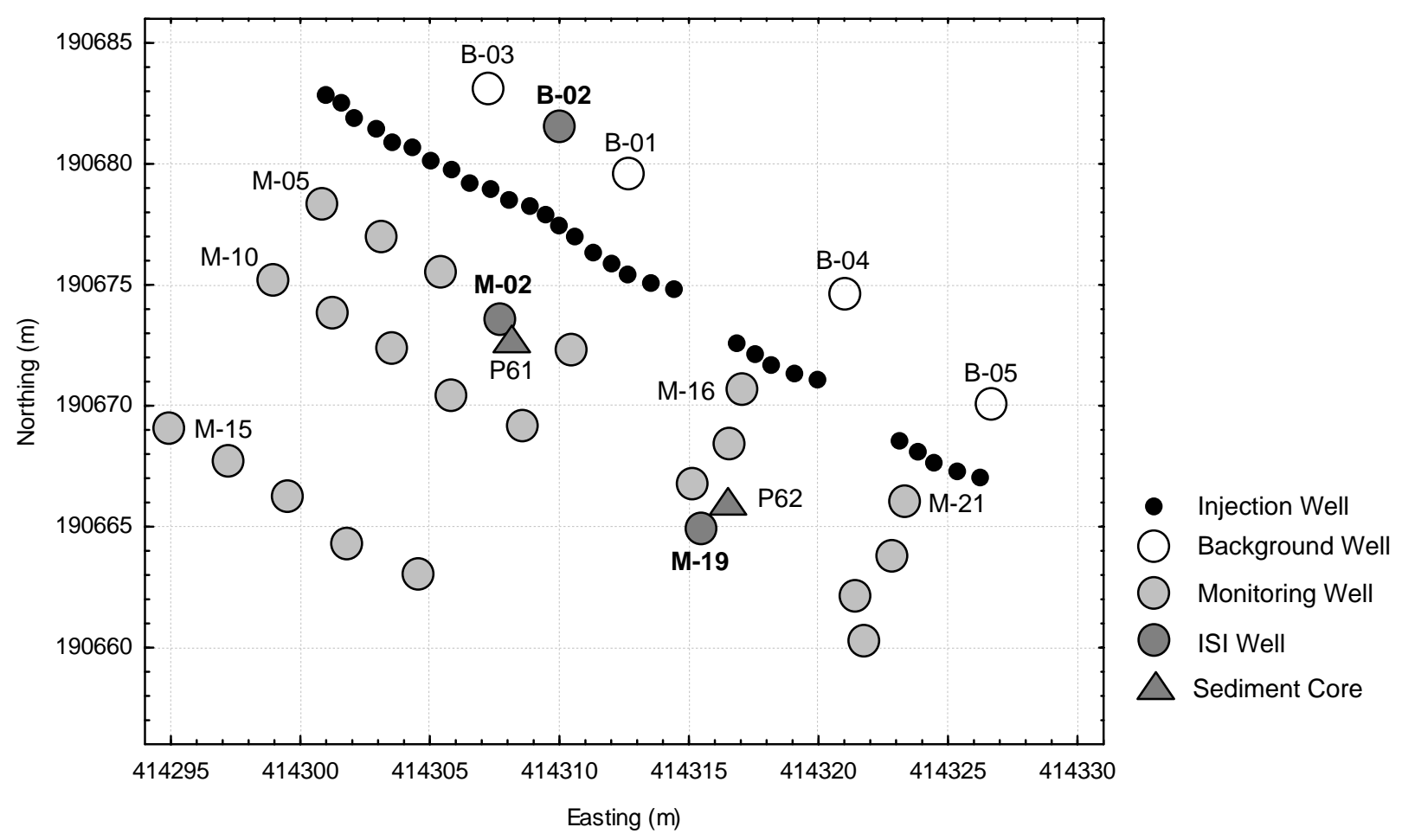

ISIs containing IR and RABS were deployed in monitoring well M-19 which had been driven to iron reducing conditions during the 2006 acetate-injection experiment which concluded in September. All incubators were deployed to a depth of approximately $4.9 \mathrm{~m}$ below top of casing. ISIs were installed on December 1, 2006 and recovered during the June 17, 2007 drilling event.

\section{Sediment Core Drilling}

Sediment cores samples adjacent to deployment wells were obtained for comparison to ISI deployed sediments. Coring was performed using a rotosonic drilling rig (Boart Longyear, Environmental and Infrastructures Services, Peoria, AZ) to a depth of $6.1 \mathrm{~m}$ below land surface (BLS). Core samples were sectioned and logged by depth. Samples from depths of approximately 4.6 to $5.2 \mathrm{~m}$ BLS were transferred to $\mathrm{N}_{2}$-filled portable glove bags and subsampled. Efforts were made to remove larger cobbles $(>3 \mathrm{~cm})$ during sampling. Samples for molecular analysis were immediately placed on dry ice and shipped to the laboratory by overnight courier and stored at $-80^{\circ} \mathrm{C}$ prior to analysis. Sediment core P-61 was adjacent to monitoring well M-02 and is referenced as M02-C; sediment core P-62 was adjacent to M-19 and has been renamed M19-C in subsequent figures. Sediment cores obtained during the drilling of the new "Winchester" gallery were considered background sediments (U-01 through U-03). 


\section{Phospholipid (PLFA) Analysis}

Sediment samples were extracted with a single-phase chloroform-methanol buffer system (17). The total lipid portion was then fractionated, using a silicic acid column, into three lipid categories: neutral lipids, glycolipids, and polar lipids (4). After fractionation, the polar lipid portion was transesterified to form fatty acid methyl esters (FAMEs) by mild alkaline methanolysis (4), as modified by Mayberry and Lane (7) to release plasmalogen ethers as dimethylacetals (DMAs). The FAMEs and DMAs were analyzed by gas chromatography/mass spectroscopy using an Agilent 6890 series gas chromatograph interfaced with an Agilent 5973 mass spectrometer.

\section{Analysis of Groundwater Samples}

Groundwater samples were collected from background wells B-03, B-04 and B-05 (adjacent to B-02) and previously stimulated monitoring wells M-16 and M-17 (near M-19) and M-08 on a monthly basis during the deployment. Groundwater parameters $(\mathrm{pH}$, dissolved oxygen, conductivity, and redox potential) were determined by using a peristaltic pump, flow cell, and multiprobe data sonde (Hydrolab-Hach Company, Chicago, IL) as detailed previously (2). All wells were purged (ca. $12 \mathrm{~L}$ ) prior to sample collection. Samples were obtained for U(VI), anion (bromide, nitrate, and sulfate), $\mathrm{Fe}(\mathrm{II})$, acetate, and sulfide analyses as previously described (2).

\section{DNA Extraction and qPCR}

DNA was extracted from recovered ISI sediments and sediment cores using the Power Soil DNA extraction kit (MO BIO Laboratories) per the manufacturer's protocol. QPCR was performed with several PCR primers sets targeting $16 \mathrm{~S}$ rDNA and functional genes to enumerate indicator genes specific for several bacterial groups involved in biotransformations at the Old Rifle site. Bacteria were enumerated by real-time PCR using PCR primers BACT1369F-PROK1492R with the TaqMan probe $1389 \mathrm{~F}$ as described previously (15). The PCR primer set $361 \mathrm{~F}-685 \mathrm{R}$ specific for the 16S rRNA gene of $\delta$-proteobacteria (14) and the TaqMan probe $1839 \mathrm{~F}$ were used as an index of potential sulfate reducing and iron reducing bacteria. Several molecular studies have indicated members of the Geobacteraceae family may be the dominant microorganisms in sediment environments in which $\mathrm{Fe}(\mathrm{III})$ reduction is the primary terminal electron accepting process $(1,6,11-13)$. PCR primer set 561F-825R and TaqMan probe Gbc2 specific for Geobacter sp. (14) were used to enumerate potential iron reducing bacteria. The 60F-461R primer pair was used to enumerate Anaeromyxobacter spp. (9). PCR primers ME1 and ME2 targeting conserved regions of the $\alpha$ subunit of the methyl coenzyme $\mathrm{M}$ reductase (mcrA) gene were used for enumeration of methanogens (5). All real-time PCR was performed on an ABI Prism 7000 Sequence Detector or an ABI 7300 Real-Time PCR System (Applied Biosystems). All experiments included control reaction mixtures without added DNA and calibration curves with appropriate positive control DNA.

\section{DGGE and Sequence Analysis}

DGGE was performed using the D-Code ${ }^{\mathrm{TM}} 16 / 16 \mathrm{~cm}$ gel system (BioRad, Hercules, CA) as described previously $(3,17)$. Gels were imaged using Labworks software (UVP, Upland, CA.). Intense bands were excised and purified using an UltraClean PCR Clean-Up DNA Purification kit (MO BIO Laboratories, Inc., Carlsbad, CA). Following purification and quantification, the excised bands were subjected to sequence analysis. Sequences were aligned with ClustalW 
(http://clustalw.genome.jp/) and refined manually. Comparative identifications and phylogenetic analysis was performed with Accelrys Gene (version 2.5, Accelrys, San Diego, CA).

\section{RESULTS AND DISCUSSION}

\section{Preliminary Deployments (B-02 and M-22)}

Two preliminary ISI deployments were conducted to examine in situ changes in microbial community composition and refine ISI design. The first ISI experiment consisted of deployment of an ISI containing both Rifle Aquifer Background Sediment (RABS) and laboratory reduced RABS (R-RABS) in a background well (B-02) to ascertain changes in microbial community composition and geochemistry/mineralogy in a microaerobic environment. The second experiment consisted of deployment of an ISI containing RABS in a previously simulated downgradient well (M-22). Following each three month deployment, the ISI was retrieved from the well and sediment samples were sent to the Center for Biomarker Analysis (CBA) at UT for phospholipid fatty acid (PLFA), denaturing gradient gel electrophoresis (DGGE), and quantitative polymerase chain reaction (qPCR) analysis.

Following incubation in B-02, the fraction of monounsaturated PLFAs decreased while the midchain branched PLFA fraction increased suggesting a shift in the community profile toward background conditions. However, no decrease in Geobacter spp. 16S rRNA gene copies as determined by qPCR was observed following deployment. An ISI containing Rifle Aquifer Background Sediment (RABS) was incubated in previously stimulated monitoring well M-22 for 3 months. The monounsaturated and branched monounsaturated PLFA fractions were significantly greater following incubation in down gradient well M-22 suggesting enrichment of $\delta$-Proteobacteria and anaerobes, respectively. Overall, the results from the initial deployments suggested that in-well sediment incubation permitted expedient interrogation of the microbial community response to field environmental perturbations and the ISIs will be a useful tool in examining the microbial community control of bio-reduced uranium. However, the 3 month timeframe of initial deployments was insufficient to adequately examine changes in microbial community composition.

\section{Geochemical Conditions during Final Deployments}

During the ISI deployment, groundwater samples were obtained from adjacent monitoring wells to evaluate predominant geochemical conditions in background (B-02), recently stimulated (M19), and previously stimulated (M-02) areas. Under background conditions, the average redox potential during the final deployment was $165.6 \mathrm{mV}$, the average dissolved oxygen concentration (DO) was $0.42 \mathrm{mg} \mathrm{L}^{-1}$, and the area could be described as mildly aerobic (Table 1). 


\begin{tabular}{|c|c|c|c|}
\hline \multicolumn{4}{|c|}{ Table 1: Summary of Geochemical Conditions } \\
\hline $\begin{array}{c}\text { Parameter } \\
\text { Mean (std dev) }\end{array}$ & $\begin{array}{c}\text { Background } \\
(\mathrm{B02})^{1}\end{array}$ & $\begin{array}{c}\text { Original Plot } \\
(\mathrm{M02})^{2}\end{array}$ & $\begin{array}{c}2004 \text { Gallery } \\
(\mathrm{M} 19)^{3}\end{array}$ \\
\hline Eh $(\mathrm{mV})$ & $165.6 \pm 55$ & $\mathbf{8 5 . 5 \pm 1 6}$ & $\mathbf{8 1 . 5} \pm \mathbf{3 6}$ \\
\hline Dissolved Oxygen $(\mathrm{mg} / \mathrm{L})$ & $0.42 \pm 0.3$ & $0.29 \pm 0.1$ & $0.54 \pm 0.5$ \\
\hline Unfiltered Fe ${ }^{2+}(\mu \mathrm{M})$ & $11.3 \pm 7$ & $\mathbf{1 0 0 \pm 3 0}$ & $\mathbf{4 1 . 2} \pm \mathbf{2 2}$ \\
\hline Filtered Fe $(\mu \mathrm{M})$ & $0.32 \pm 0.3$ & $\mathbf{3 . 3 1} \pm \mathbf{0 . 1}$ & $\mathbf{1 . 5 4} \pm \mathbf{0 . 8}$ \\
\hline Sulfate $(\mathrm{mM})$ & $10.36 \pm 1.3$ & $11.93 \pm 1.3$ & $10.19 \pm 1.7$ \\
\hline Unfiltered Sulfide $(\mu \mathrm{M})$ & $0.9 \pm 1.6$ & $1.28 \pm 0.5$ & $2.18 \pm 4.4$ \\
\hline Uranium $(\mu \mathrm{M})$ & $1.22 \pm 0.4$ & $0.97 \pm 0.5$ & $1.13 \pm 0.4$ \\
\hline
\end{tabular}

Mean values \pm standard deviation for monthly monitoring events (11/06 through 6/07).

Bold indicates significantly different than background $(\alpha=0.05)$

${ }^{1}$ Includes background wells B03, B04, and B05

${ }^{2}$ Includes M08 in the original test plot

${ }^{3}$ Includes M16 and M17 of the 2006 test plot

Conversely, redox potentials in the vicinity of M-02 $(85.5 \mathrm{mV})$ and $\mathrm{M}-19(81.5 \mathrm{mV})$ were significantly lower than under background conditions $(\alpha=0.05)$. Likewise, dissolved ferrous iron concentrations in the M-02 and M-19 areas were significantly greater than background as was expected for previously stimulated wells. Based on dissolved sulfate and sulfide concentrations, dissimilatory sulfate reduction was not significant in background or previously stimulated areas (Table 1).

\section{Hierarchical Cluster Analysis of PLFA Profiles}

An exploratory hierarchical cluster analysis (Ward's Method) based on PLFA profiles revealed two primary clusters (Figure 6) composed in general of Background/RABS (A) and reduced sediments (B). The background and RABS associated primary cluster (A) contained

Figure 6: Hierarchical Cluster Analysis Ward's method

Euclidean distances

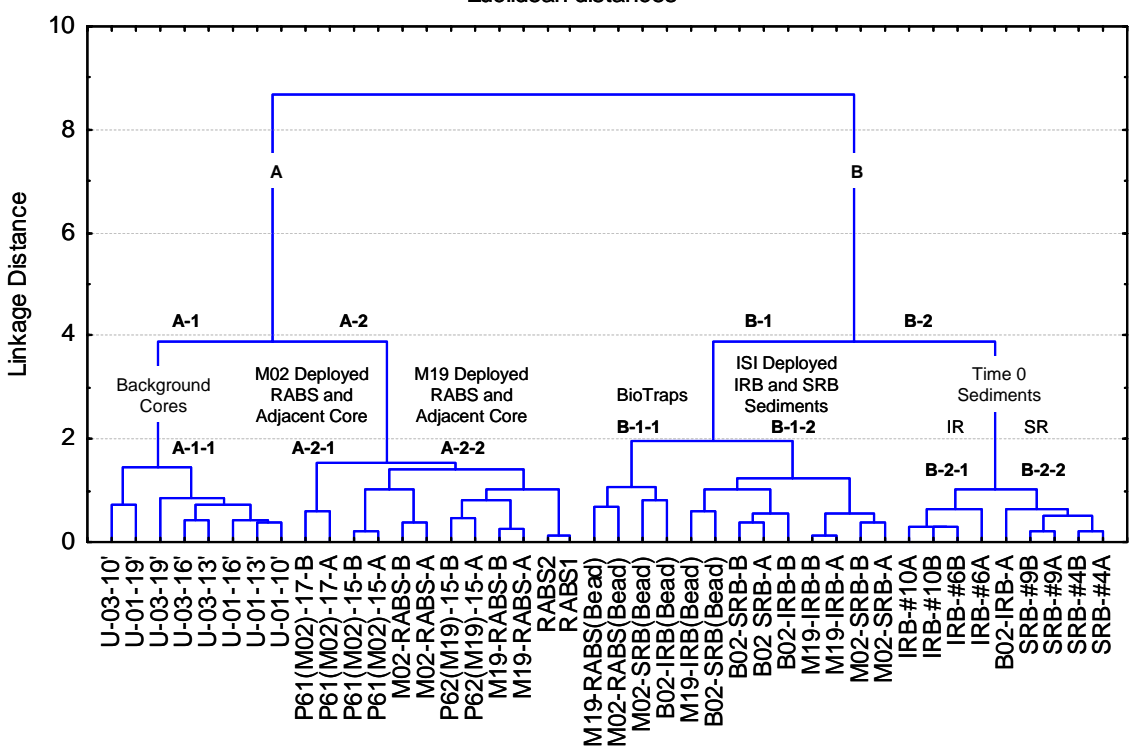
significantly greater midchain branched-, terminally branched-, and branched monounsaturated-fatty acids whereas primary cluster B had significantly greater monounsaturates suggesting enrichment of Proteobacteria in the reduced sediments. Within primary cluster A, the background sediment core samples U-01 and U-03 formed a secondary cluster (A-1) distinct from the A-2 secondary cluster which contained RABS, ISI deployed RABS, and adjacent sediment core samples. Tertiary (A-2-2) 
and quaternary structure subclusters were also noted. ISI incubated RABS deployed in M-02 and M-19 were more similar to their corresponding sediment core samples than to each other and the RABS (time 0) subcluster suggesting that the ISI microbial community composition responded to local (reducing) subsurface conditions. Primary cluster B also showed distinct secondary structure where ISI deployed reduced sediments (B-1) and time 0 reduced sediments (B-2) formed unique clades indicating shifts in microbial community composition during ISI deployment. Within the secondary B-1 cluster, reduced sediment deployed in background well B-02, iron reducing sediment deployed in previously stimulated well M-19, and sulfate reducing sediment incubated in M-02 all formed distinct subclusters likely due to different geochemical conditions at each well.

\section{Changes in Microbial Community Composition during ISI Deployment}

\section{Microbial Community Composition Prior to ISI Deployment (time 0)}

The hierarchical cluster analysis of PLFA profiles discussed previously clearly indicated changes in the sediment microbial community composition during ISI deployments and suggested that observed shifts in sediment microbial populations were related to both the redox state of the time 0 sediment and subsurface conditions (Deployment Well). Subsamples of Rifle Aquifer Background Sediment (RABS), Rifle sediment under iron-reducing conditions (IR), and Rifle sediment under sulfate reducing conditions (SR) were obtained for baseline PLFA profiles, enumeration of specific bacterial groups, and DGGE profiles with sequence analysis prior to ISI deployment (Figure 7 ). In RABS, monounsaturates $(\sim 34 \%)$ were the dominant PLFA but

Figure 7: Microbial Community Composition of Time 0 Sediments
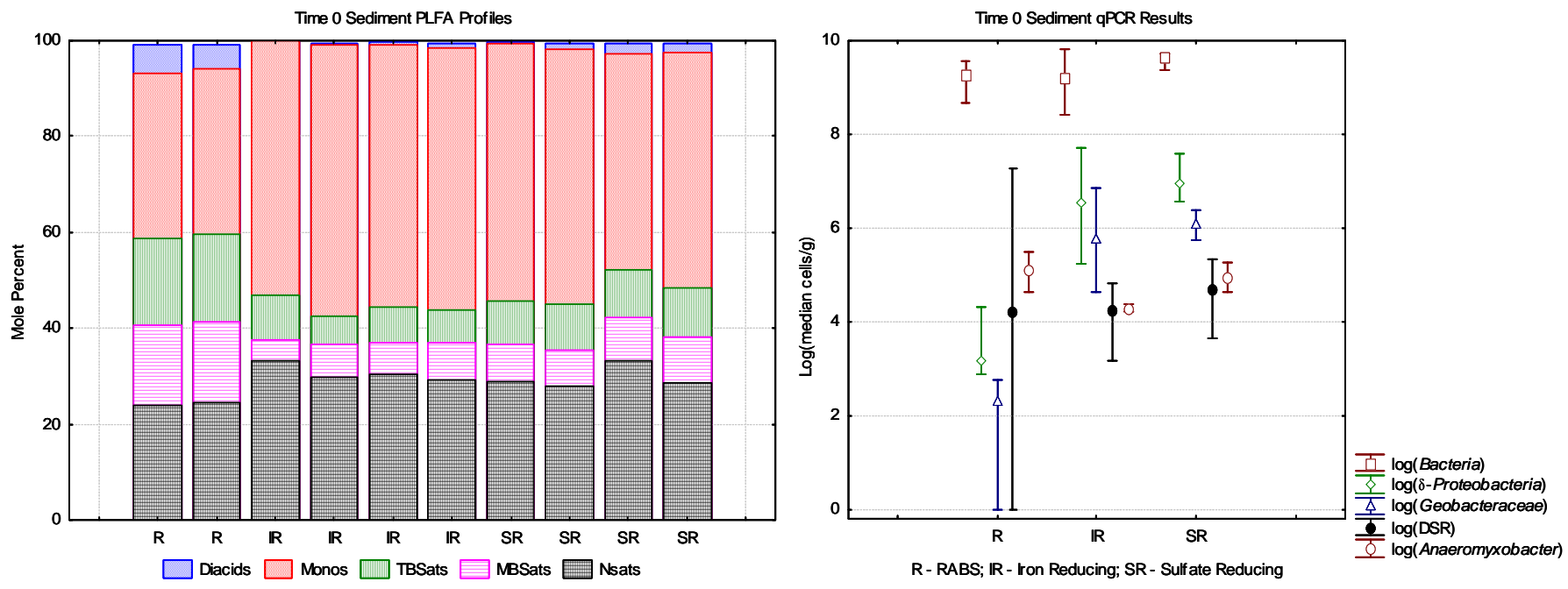

saturates $(\sim 24 \%)$, mid-chain branched $(\sim 17 \%)$ and terminally-branched $(\sim 18 \%)$ PLFAs were all significant fractions. The $\delta$-Proteobacteria population $\left(10^{3}\right.$ cells $\left./ \mathrm{g}\right)$, used as an index of iron and sulfate reducing bacteria, and Geobacteraceae population $\left(10^{2}\right.$ cells/g) were relatively low as anticipated for oxidized sediments. The median sulfate reducer population as indicated by quantification of dissimilatory sulfite reductase (DSR) gene copies was on the order of $10^{4}$ cells $/ \mathrm{g}$, but replicates ranged from below the quantitation limit to as high as $10^{7}$ cells $/ \mathrm{g}$. Based on sequences of dominant bands in the DGGE profiles, Chloroflexi (green nonsulfur bacteria), Actinobacteria, and Acidobacteria appeared to be the dominant members of the microbial 
community in background sediments. In previous clone library results, green sulfur/nonsulfur bacteria were the most prevalent followed by Acidobacteria, $\alpha$-Proteobacteria, and Actinobacteria (16).

When driven to iron reducing conditions (IR) and sulfate reducing conditions (SR) in the laboratory, $\delta$-Proteobacteria and Geobacteraceae cell densities increased significantly $(\alpha=0.05)$. Likewise, the mole fraction of monounsaturates, an indicator of Proteobacteria, increased significantly and 16S rRNA gene sequences corresponding to $\delta$-Proteobacteria were recovered from DGGE profiles of iron reducing sediment. Despite being driven to sulfate reducing conditions (SR), no significant increases in dissimilatory sulfite reductase (DSR) gene copies were noted.

Figure 8: ISI Deployed RABS and Sediment Cores

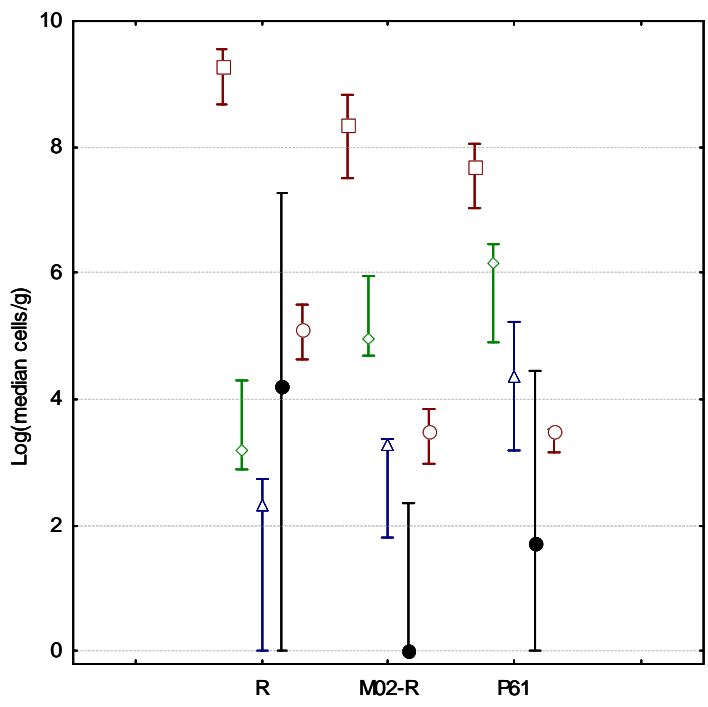

R - RABS; M02-R - ISI Deployed RABS; P61 - Adjacent Core

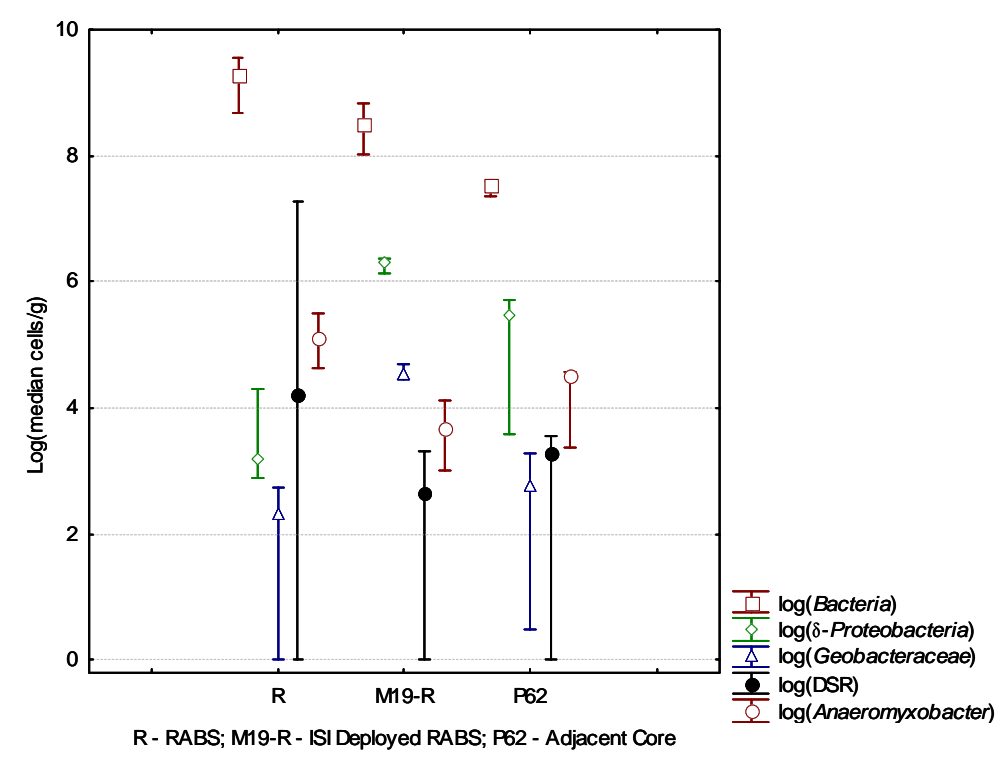

\section{ISI Deployed RABS}

An ISI containing RABS was deployed in M-02 located in the original test plot which last received acetate in 2005. As mentioned previously, the redox potential of the original test plot during the ISI deployment was significantly lower than in background wells (Table 1). $\mathrm{Fe}^{2+}$ production and the lack of sulfate consumption suggested predominantly iron reducing conditions. During RABS in well incubation in $\mathrm{M}-02$, the $\delta$ Proteobacterial population increased significantly (Figure 8). Likewise, Geobacteraceae increased by an order of magnitude indicating enrichment of iron reducing bacteria in the ISI deployed RABS. DSR gene copies decreased to below quantitation limits which was consistent with the observed decrease in mid-chained branched saturates and environmental conditions.

An ISI containing RABS was also deployed in downgradient well M-19 located in the 2005 gallery which last received acetate three months prior to ISI installation. As with M-02, the redox potential of M-19 was significantly lower than background and $\mathrm{Fe}^{2+}$ and sulfate concentrations 
indicated iron reducing conditions during deployment (Table 1). During the incubation of RABS in M-19, $\delta$-Proteobacteria and Geobacteraceae populations increased significantly while DSR copies decreased which corresponds to increases in monounsaturates and decreases in midchained branched saturates, respectively (Figure 8).

To determine whether the results for the ISI deployed RABS could be extrapolated to the native aquifer sediments, qPCR results were compared to those of adjacent sediment core samples obtained at the end of the deployment. As noted previously, the PLFA profiles of M02-R were most similar to those of the adjacent P-61 sediment core at a depth of 15 feet. The abundances of $\delta$-Proteobacteria and Geobacteraceae were slightly lower in the M02-IR than in P-61, however, no significant differences were noted between the microbial community composition of the P-61 sediment core and recovered ISI sediments $(\alpha=0.05)$. Furthermore, the increase in $\delta$ Proteobacteria and Geobacteraceae follows the observed trend between the RABS and the native sediment. As with M-02, the PLFA profiles of M19-R were most closely related to those of the adjacent sediment core P-62. Again, the abundance of potential iron reducing bacteria in M19-R did not precisely match those of the P-62 core, but Proteobacteria and Geobacteraceae cell densities were greater than in the RABS showing the response of the microbial community to environmental conditions. Overall, results for the ISI deployed RABS indicated enrichment of iron reducing bacteria consistent with subsurface conditions and suggested that ISI deployed sediments would respond to local geochemical conditions and could serve as a surrogate for sediment core samples.

\section{ISI Deployed Iron Reducing (IR) Sediment}

An ISI containing Rifle sediment driven to iron reducing conditions was deployed in background well B-02 located upgradient of the original test plot to determine whether the ISIs could be used to examine the impact of the influx of oxidized background groundwater on the stability of bioreduced uranium. Dissolved oxygen in the background wells during the ISI deployment was relatively low $(\sim 0.42 \mathrm{mg} / \mathrm{L})$, but the redox potential was significantly greater than in downgradient wells (Table 1). Furthermore, $\mathrm{Fe}^{2+}$ concentrations were lower than in previously stimulated wells suggesting mildly aerobic background conditions. Despite oxidizing conditions, no significant changes were evident in the PLFA profile and median $\delta$ Proteobacteria and Geobacteraceae populations in B02-IR remained on the order of $10^{6}$ and $10^{4}$ cells/g respectively during ISI deployment. DSR gene copies decreased from $10^{4}$ cells $/ \mathrm{g}$ to below quantitation limits. Again, ISI sediment results were compared to sediment cores to evaluate the feasibility of ISIs as surrogates for sediment cores. The $\delta$-Proteobacteria and Geobacteraceae cell densities following deployment in B02 were significantly greater than in background sediment core samples U-01 and U-03. Although seemingly counter-intuitive, the timeframe of ISI deployment must be considered during interpretation. ISIs containing biostimulated sediments were deployed in B- 02 for approximately seven months whereas the background U sediments have never been biostimulated. Instead, the B02-IR results should be compared to those of the previously stimulated sediment cores. In P-61 sediment cores, $\delta$ Proteobacteria and Geobacteraceae abundances ranged from $10^{4}$ to $10^{6}$ cells/g two years after acetate injection had stopped which is comparable to the $10^{5}$ to $10^{6}$ cells/g detected in B02-IR (Figure 9). DSR copies in the B-02 deployed iron reducing sediment were significantly lower than in the P-61 sediment core. However, the IR sediment deployed in the B-02 ISI had not been driven to sulfate reducing conditions whereas the original test plot had subject to repeated acetate 
injections and sulfate reduction. Overall, the B-02 ISI results appear consistent with site observations that rapid changes in the sediment microbial community composition do not occur at the site following cessation of electron donor addition.

An ISI containing IR sediment was also deployed in recently stimulated well M-19. Following in-well incubation, $\delta$-Proteobacterial cell densities remained at approximately $10^{6}$ cells $/ \mathrm{g}$ although Geobacteraceae decreased by approximately an order of magnitude to $\sim 10^{4}$ cells $/ \mathrm{g}$. Likewise, DSR copies decreased by an order of magnitude but remained above quantitation limits. Median $\delta$-Proteobacteria and Geobacteraceae cell densities in M-19 deployed IR were approximately an order of magnitude greater than in the adjacent P-62 sediment core samples although the differences were not statistically significant. Sulfate reducing bacteria in both the M-19 deployed IR and the sediment core were on the order of $10^{3}$ cells/g. The lack of significant shifts in the sediment microbial community are consistent with environmental conditions and the type of deployed sediment. Specifically, Rifle sediment driven to iron reducing conditions was incubated in recently stimulated well M-19 under predominantly iron reducing conditions.

Figure 9: ISI Deployed Iron Reducing Sediment and Sediment Cores
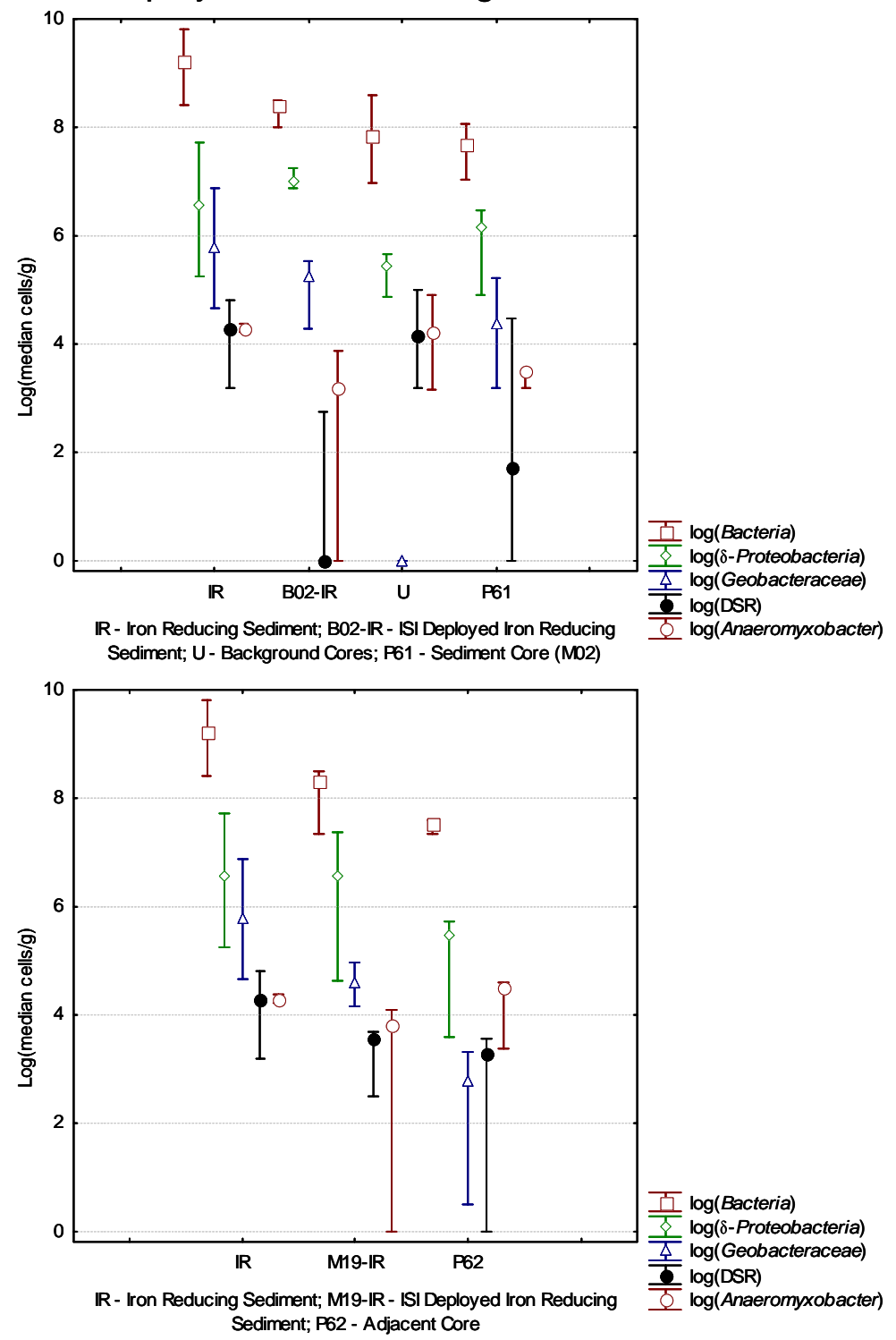


\section{ISI Deployed Sulfate Reducing (SR) Sediment}

An ISI containing Rifle sediment under sulfate reducing conditions (SR) was deployed in background well B-02. Following in-well incubation in B-02, significant changes in the PLFA profile and qPCR results were evident. Most notably, the fraction of mid-chain branched saturates and branched monounsaturates decreased significantly suggesting a decrease in sulfate reducers and anaerobic bacteria, respectively. Based on qPCR results, $\delta$-Proteobacteria and Geobacteraceae decreased in the ISI deployed B02-SR but were still on the order of $10^{6}$ and $10^{4}$ cells/g, respectively. The population of sulfate reducing bacteria as indicated by enumeration of DSR gene copies decreased from $10^{4}$ cells/g to below quantitation limits. As with the IR sediments, the microbial community composition of the B-02 deployed sulfate reducing sediments was significantly different than that of the background core samples (U-01 and U-03) as would be anticipated. When B02-SR results were compared to those of the previously stimulated core P-61 only minor differences in microbial community composition were noted. $\delta$ Proteobacteria and Geobacteraceae were approximately $10^{6}$ and $10^{4}$ cells/g in B02-SR and in P61 samples. Although not statistically significant, DSR copies in P61 samples were slightly greater than in B02-SR which was reflected in greater fraction of mid-chain branched saturates in the P-61 PLFA profile. As with the iron reducing sediment deployed in B-02, the results for the sulfate reducing sediments deployed in B-02 indicated that rapid changes in the sediment microbial community composition did not occur which is consistent with the site observation that up to $85 \%$ of influent $\mathrm{U}(\mathrm{VI})$ is removed even a year after the cessation of electron donor addition.

Sulfate reducing sediments were also deployed in downgradient well M-02 located in the original test plot which last received acetate in 2005. The redox potential of the original test plot during the ISI deployment was significantly lower than in background wells (Table 1). $\mathrm{Fe}^{2+}$ production and the lack of sulfate consumption suggested predominantly iron reducing conditions. Following M-02 deployment, the abundance of $\delta$-Proteobacteria decreased slightly but not significantly. Geobacteraceae also decreased but were still present on the order of $10^{4}$ cells/g. DSR gene copies decreased from approximately $10^{4}$ cells/g to below quantitation limits which corresponded to a decrease in the mid-chain branched saturate fraction. When compared to the adjacent sediment core sample P-61, no significant differences in qPCR results were noted. The $\delta$-Proteobacteria populations in both the recovered ISI and P-61 sediment cores were approximately $10^{6}$ cells/g. Similarly, Geobacteraceae were slightly lower in the sediment core but were within an order of magnitude of the cell density detected in M02-SR. Sulfate reducers were detected in P-61 but were near quantitation limits.

\section{DGGE Profiles and 16S rRNA Gene Sequences}

\section{Microbial Community Composition Prior to ISI Deployment (time 0)}

The DGGE profiles of the background sediments (RABS) were faint smears of PCR products with 4-5 discernable bands which is typical for profiles of unstimulated soils. The nucleotide sequences of select bands were determined to assess potentially important members of the bacterial community in the background sediment. Based on sequences of dominant bands in the DGGE profiles, Chloroflexi (green nonsulfur bacteria), Actinobacteria, and Acidobacteria appeared to be the dominant members of the microbial community in background sediments. In previous clone library results, green sulfur/nonsulfur bacteria were the most prevalent followed 
by Acidobacteria, $\alpha$-Proteobacteria, and Actinobacteria (16). DGGE profiles for laboratory stimulated sediment under iron-reducing conditions (IR) were considerably more diverse. In addition to the Chloroflexi, Actinobacteria, and Acidobacteria present in the background sediment, 16S rRNA gene sequences corresponding to $\delta$-Proteobacteria and $\gamma$-Proteobacteria were also evident in IR profiles. Despite iron-reducing conditions and the detection of Geobacteraceae by qPCR, no Geobacter sequences were recovered from IR profiles. Based on sequences selected form SR, Firmicutes (primarily Clostridia and Bacilli) were enriched under sulfate reducing conditions in the laboratory. A similar Firmicutes bloom was noted in M-08 following field biostimulation experiments (16). Unlike earlier results, however, Desulfobacterales sequences were not recovered from SR prior to ISI deployment.

\section{ISI Deployed RABS}

ISIs containing RABS were deployed in previously stimulated wells M-02 and M-19. Based on monthly geochemical measurements, the subsurface in the vicinity of both wells was under iron reducing conditions during the deployment. Significant shifts in the RABS microbial community composition were noted following ISI deployments. Geobacteraceae and Desulfobacterales sequences not detected in RABS prior to deployment were present in RABS samples after incubation in both M-02 and M-19. Desulfosporosinus sequences were also prevalent in M-19 deployed RABS. Overall, the observed shifts in RABS microbial community composition indicate a response to the prevailing reducing conditions during deployment consistent with recovered core samples, qPCR, and previous results.

\section{ISI Deployed Iron Reducing Sediment}

ISIs containing iron reducing sediment were installed in background monitoring well B-02 and downgradient well M-19. Based on selected DGGE bands alone, the IR microbial community composition did not appear to change dramatically following in well incubation. Sequences from $\gamma$-Proteobacteria, Actinobacteria, and Bacteroidales were present in IR prior to and after deployment B02-IR and M19-IR. Geobacteraceae sequences were detected in IR after deployment in B-02, but were also detected by qPCR prior to in well incubation.

\section{ISI Deployed Sulfate Reducing Sediment}

ISIs containing sulfate reducing sediment were deployed in B-02 and M-02. Based on DGGE profiles and subsequent sequencing of selected PCR products, the SR microbial community composition appeared to be dominated by Firmicutes prior to deployment. Following incubation in B-02, most recovered sequences were similar to Bacteroidales although $\gamma$-Proteobacteria and Actinobacteria sequences were also noted suggesting some shift in community composition. $\gamma$ Proteobacteria and Actinobacteria sequences were also found in SR deployed in M-02, however, most sequences belonged to the $\delta$-Proteobacteria group indicating a shift in community composition consistent with observed reducing conditions. 


\section{ISIs as Monitoring Tools}

Field scale acetate injections at the Old Rifle site have repeatedly demonstrated that electron donor addition stimulates growth of iron reducing bacteria, most notably Geobacteraceae, promoting bioreduction of dissolved U(VI). After depletion of bioavailable Fe(III) and the onset of sulfate reducing conditions, loss of U(VI) from solution is significantly lower than under iron reducing conditions. However, U(VI) removal in the post-biostimulation phase continues longer than expected considering the known susceptibility of U(IV) to reoxidation. In fact, up to $85 \%$ of influent U(VI) is removed even a year after the cessation of electron donor addition. While the processes governing U(VI) reduction during the biostimulation phase are reasonably well characterized, the key factors controlling maintenance of bioreduced uranium remain poorly understood. The continued U(VI) removal may be the result of complex interactions involving sorption of U(VI) to Fe(III) oxides during shifts to more oxidizing conditions, sorption of U(VI) to microbial cells, the $\mathrm{O}_{2}$ buffering capacity of iron sulfides formed during the sulfate reduction phase, or U(VI) sorption to Fe-containing octahedral-layer edge sites. Regardless of the mechanism, however, the common denominator with these hypotheses is that important microbial and abiotic interactions may be associated with the subsurface sediment.

Collection of sediment core samples provides the most direct avenue to explore biotic and abiotic interactions associated with the sediment, but, repeated drilling is expensive and not always practical especially to assess temporal changes. BioTrap samplers containing Bio-Sep beads have been utilized at the site, but the analysis of any surrogate solid phase is likely to have its own inherent set of biases. Furthermore, the use of sediment surrogates does not allow for interrogation of the effect of minerals present in the native material. The ISIs were developed as a compromise between repeated drilling for sediment cores and the use of sediment surrogates permitting field deployment of amended and native sediments in a readily recovered/sampled platform. The cornerstone of the ISI approach is that analysis of ISI deployed sediments will provide interpretable results consistent with sediment samples which are more difficult and expensive to obtain.

The ISI method offers a unique approach to investigate microbial community dynamics in a field expedient platform but could potentially be limited by the extent to which observations can be extrapolated to the broader aquifer system. Overall however, the results of the ISI deployments at the Old Rifle site show that ISIs can serve as surrogates or supplements to sediment core drilling. When oxidized Rifle aquifer background sediments (RABS) were deployed in previously stimulated wells under iron reducing conditions, cell densities of known iron reducing bacteria including Geobacteraceae increased significantly shown the microbial community response to local subsurface conditions. Moreover, the PLFA profiles of RABS following in situ deployment were strikingly similar to those of adjacent sediment cores (Hierarchical Cluster Analysis; Figure 6) strongly suggesting ISI results could be extrapolated to the native material of the test plots. Results for ISI deployed reduced sediments are less readily interpreted but nonetheless point toward the ability of the ISIs to monitor microbial community response to subsurface conditions. First, PLFA profiles of reduced sediments following ISI deployment were significantly different from the time 0 starting materials demonstrating a shift in the sediment microbial community. Secondly, hierarchical cluster analysis of PLFA profiles revealed subclusters based on deployment well suggesting differences were based on geochemical conditions. For reduced sediments deployed in B-02, populations of iron reducing 
bacteria decreased in general as did total biomass but were at least comparable to the sediment core samples. When reduced sediments were deployed in previously stimulated wells, populations of iron reducing bacteria in ISI deployed sediments in general only decreased slightly and seemed to represent a time dependent shift toward the microbial community composition of the adjacent, native sediment of the test plots which raises an important point. The ISI deployed sediment were amended with electron donor once and incubated in situ for seven months whereas the test plots were subject to repeated cycles of acetate injections. Thus, differences in the microbial community composition between ISI deployed reduced sediments and the P-61 and P-62 sediment cores should be expected. In terms of validating the ISI approach at the Old Rifle site however, the overall results demonstrate the ISIs can be used as in situ recorders of changes in sediment microbial community composition. Furthermore, the ISIs will be particularly beneficial when integrated into future field experiments.

\section{Implications for the Role of Sulfate Reducing Bacteria}

The results of the 2003 field experiments at the Old Rifle sited point to three distinct phases of uranium removal as summarized by N'Guessan et al. (8): (I) acetate injection promoting iron and uranium reduction followed by (II) depletion of $\mathrm{Fe}^{3+}$ and the onset of sulfate reduction and (III) continued $\mathrm{U}(\mathrm{VI})$ removal more than a year after cessation of donor addition. This continued uranium removal prompted examination of the mechanism of uranium removal in the absence of acetate along with the apparent stability of bioreduced uranium. The ISIs were developed with the purpose of investigating the role of sulfate reducing bacteria either through direct U(VI) reduction or production of $\mathrm{FeS}_{0.9}$ in this process. While a definitive role for SRB cannot be identified solely on the basis of this project, the results do support the observations of on-going field activities and a recently published report (8) that the actions of SRB are not likely to be directly involved in continued uranium removal. The hypothesis that SRB play a role in continued uranium removal was driven by the proliferation of SRB following depletion of ferric iron and the ability of some SRB to directly reduce $\mathrm{U}(\mathrm{VI})$. In the current study however, DSR gene copy numbers were low in previously (P-61) and recently (P-62) sediment core samples casting some doubt on direct $\mathrm{U}(\mathrm{VI})$ reduction by SRB accounting for the observed removal of $85 \%$ of influent U(VI). Furthermore, N'Guessan et al. (8) demonstrated that in microbially reduced sediments loss of soluble U(VI) was accompanied by an increase in U(VI) associated with the sediment whereas neither were observed with background sediment indicating U(VI) sorption rather than microbial reduction. N'Guessan et al. also showed that heat treatment eliminated the capacity for $\mathrm{U}(\mathrm{VI})$ removal from groundwater in the absence of acetate suggesting abiotic U(VI) reduction by iron sulfides was unlikely. Instead, N'Guessan et al. suggest continued uranium removal in the absence of acetate could be due to U(VI) sorption by Firmicutes.

\section{Synergistic Activities}

In collaboration with Ken Williams (LBL), newly fabricated ISIs have been equipped with complex resistivity probes to monitor changes in bulk mineralogy and graphite anodes to correlate current flow with acetate oxidation. 
In collaboration with Darrell Chandler (Akonni Biosystems), preliminary microarray analysis was performed with iron-reducing sediment prior to ISI deployment. Although microarray protocols must be optimized the initial analysis indicated enrichment of Geobacteraceae in ironreducing ISI sediments prior to the final deployment.

Center for Biomarker Analysis personnel assisted PNNL in all aspects of the field activities for the 2004, 2005, and 2006 biostimulation experiments.

\section{Publications}

Note: In review publications were also supported by the Rifle IFC under contract DE AC05 76RL01830

Yun-Juan Chang, Philip E. Long, Roland Geyer, Aaron D. Peacock, Charles T. Resch, Kerry Sublette, Susan Pfiffner, Amanda Smithgall, Robert T. Anderson, Helen A. Vrionis, John R.Stephen, Richard Dayvault, Irene Ortiz-Bernad, Derek R. Lovley, and David C. White. 2005. Microbial Incorporation of ${ }^{13} \mathrm{C}$-Labeled Acetate at the Field Scale: Detection of Microbes Responsible for Reduction of U(VI). Environmental Science and Technology 39(23), 9039 9048 .

Darrell P. Chandler, Ann E. Jarrell, Eric R. Roden, Julia Golova, Boris Chernov, Matthew J. Schipma, Aaron D. Peacock, and Philip E. Long. 2006. Suspension Array Analysis of 16S rRNA from $\mathrm{Fe}$ - and $\mathrm{SO}_{4}{ }^{2-}$ Reducing Bacteria in Uranium Contaminated Sediments Undergoing Bioremediation. Applied and Environmental Microbiology, 72(7), 4672-4687.

B.R. Baldwin, A.D. Peacock, M. Park, D.M. Ogles, J.D. Istok, J.P. McKinley, C.T. Resch, and D.C. White. Multilevel Samplers to Assess Microbial Community Response to Biostimulation. Ground Water, 46(2), 295-304.

Hedrick, D.B., A.D. Peacock, D.R. Lovley, T.L. Woodard, K.P. Nevin, P.E. Long and D.C. White. 2008. Polar Lipid Fatty Acids, LPS-Hydroxy Fatty Acids, and Respiratory Quinones of Three Geobacter Strains, and Variation with Electron Acceptor. Archives of Microbiology (in review).

Komlos, J., A.D. Peacock, R.K. Kukkadapu, and P.R. Jaffe. 2008. Long-Term Dynamics of Uranium Reduction/Reoxidation under Low Sulfate Conditions. Geochemica et Cosmochemica Acta (in review).

\section{REFERENCES CITED}

1. Anderson, R. T., J. N. Rooney-Varga, C. V. Gaw, and D. R. Lovley. 1998. Anaerobic Benzene Oxidation in the Fe(III) Reduction Zone of Petroleum-Contaminated Aquifers. Environmental Science \& Technology 32:1222-1229.

2. Anderson, R. T., H. A. Vrionis, I. Ortiz-Bernad, C. T. Resch, P. E. Long, R. Dayvault, K. Karp, S. Marutzky, D. R. Metzler, A. Peacock, D. C. White, M. Lowe, 
and D. R. Lovley. 2003. Stimulating the In Situ Activity of Geobacter Species To Remove Uranium from the Groundwater of a Uranium-Contaminated Aquifer. Applied and Environmental Microbiology 69:5884-5891.

3. Chang, Y.-J., J. R. Stephen, A. P. Richter, A. D. Venosa, J. Bruggemann, S. J. Macnaughton, G. A. Kowalchuk, J. R. Haines, E. Kline, and D. C. White. 2000. Phylogenetic analysis of aerobic freshwater and marine enrichment cultures efficient in hydrocarbon degradation: effect of profiling method. Journal of Microbiological Methods 40:19.

4. Guckert, J. B., C. P. Antworth, P. D. Nichols, and D. C. White. 1985. Phospholipid, ester-linked fatty acid profiles as reproducible assays for changes in prokaryotic community structure of estuarine sediments. FEMS microbiology ecology 31:147-158.

5. Hales, B., C. Edwards, D. Ritchie, G. Hall, R. Pickup, and J. Saunders. 1996. Isolation and identification of methanogen-specific DNA from blanket bog peat by PCR amplification and sequence analysis. Applied and Environmental Microbiology 62:668675.

6. Holmes, D. E., K. T. Finneran, R. A. O'Neil, and D. R. Lovley. 2002. Enrichment of Members of the Family Geobacteraceae Associated with Stimulation of Dissimilatory Metal Reduction in Uranium-Contaminated Aquifer Sediments. Applied and Environmental Microbiology 68:2300-2306.

7. Mayberry, W. R., and J. R. Lane. 1993. Sequential alkaline saponification/acid hydrolysis/ esterification: a one-tube method with enhanced recovery of both cyclopropane and hydroxylated fatty acids. Journal of Microbiological Methods 18:21.

8. N'Guessan, A. L., H. A. Vrionis, C. T. Resch, P. E. Long, and D. R. Lovley. 2008. Sustained Removal of Uranium From Contaminated Groundwater Following Stimulation of Dissimilatory Metal Reduction. Environmental Science \& Technology in press.

9. Petrie, L., N. N. North, S. L. Dollhopf, D. L. Balkwill, and J. E. Kostka. 2003. Enumeration and Characterization of Iron(III)-Reducing Microbial Communities from Acidic Subsurface Sediments Contaminated with Uranium(VI). Appl Environ Microbiol. 69:7467-7479.

10. Phelps, T. J., E. G. Raione, D. C. White, and C. B. Fliermans. 1989. Microbial activity in deep surface environments. Geomicrobiology Journal 8:79-91.

11. Roling, W. F. M., B. M. van Breukelen, M. Braster, B. Lin, and H. W. van Verseveld. 2001. Relationships between Microbial Community Structure and Hydrochemistry in a Landfill Leachate-Polluted Aquifer. Applied and Environmental Microbiology 67:4619-4629.

12. Rooney-Varga, J. N., R. T. Anderson, J. L. Fraga, D. Ringelberg, and D. R. Lovley. 1999. Microbial Communities Associated with Anaerobic Benzene Degradation in a Petroleum-Contaminated Aquifer. Applied and Environmental Microbiology 65:30563063.

13. Snoeyenbos-West, O. L., K. P. Nevin, R. T. Anderson, and D. R. Lovley. 2000. Enrichment of $<$ e7 $>$ Geobacter $</$ e $7>$ Species in Response to Stimulation of Fe(III) Reduction in Sandy Aquifer Sediments. Microbial Ecology 39:153-167.

14. Stults, J. R., O. Snoeyenbos-West, B. Methe, D. R. Lovley, and D. P. Chandler. 2001. Application of the 5' Fluorogenic Exonuclease Assay (TaqMan) for Quantitative Ribosomal DNA and rRNA Analysis in Sediments. Applied and Environmental Microbiology 67:2781-2789. 
15. Suzuki, M. T., L. T. Taylor, and E. F. DeLong. 2000. Quantitative Analysis of SmallSubunit rRNA Genes in Mixed Microbial Populations via 5'-Nuclease Assays. Applied and Environmental Microbiology 66:4605-4614.

16. Vrionis, H. A., R. T. Anderson, I. Ortiz-Bernad, K. R. O'Neill, C. T. Resch, A. D. Peacock, R. Dayvault, D. C. White, P. E. Long, and D. R. Lovley. 2005. Microbiological and Geochemical Heterogeneity in an In Situ Uranium Bioremediation Field Site. Applied and Environmental Microbiology 71:6308-6318.

17. White, D. C., R. J. Bobbie, J. S. Heron, J. D. King, and S. J. Morrison. 1979.

Biochemical measurements of microbial mass and activity from environmental samples. In J. W. Costerton and R. R. Colwell (ed.), Native aquatic bacteria: enumeration, activity and ecology, vol. ASTM STP 695. American Society for Testing and Materials, Philadelphia, PA. 